九州大学学術情報リポジトリ

Kyushu University Institutional Repository

\title{
Mineralogy of Laterite Samples from Viet Nam and Their Use as Flocculating Agents for the Removal of Clay Suspensions
}

\section{Nga, Nguyen Thi Hang}

Laboratory of Environmental Geochemistry, Division of Bioproduction Environmental Sciences, Department of Agro-environmental Sciences, Graduate School of Bioresource and Bioenvironmental Sciences, Kyushu University

\section{Mori, Yuki}

Laboratory of Environmental Geochemistry, Division of Bioproduction Environmental Sciences, Department of Agro-environmental Sciences, Faculty of Agriculture, Kyushu University

Wada, Shin-Ichiro

Laboratory of Environmental Geochemistry, Division of Bioproduction Environmental Sciences,

Department of Agro-environmental Sciences, Faculty of Agriculture, Kyushu University

https://doi.org/10.5109/26177

出版情報: 九州大学大学院農学研究院紀要. 58 (1)，pp.167-173，2013-02. Faculty of Agriculture， Kyushu University

バージョン :

権利関係 : 


\title{
Mineralogy of Laterite Samples from Viet Nam and Their Use as Flocculating Agents for the Removal of Clay Suspensions
}

\author{
Nguyen Thi Hang NGA ${ }^{1}$, Yuki MORI and Shin-Ichiro WADA*
}

\author{
Laboratory of Environmental Geochemistry, Division of Bioproduction Environmental Sciences, \\ Department of Agro-environmental Sciences, Faculty of Agriculture, \\ Kyushu University, Fukuoka 812-8581, Japan \\ (Received October 31, 2012 and accepted November 8, 2012)
}

\begin{abstract}
The existence of clay suspended particles is one of main factors increasing turbidity in water. Flocculation is a common technique used to eliminate suspended materials from water. Currently, a variety of flocculating agents have been found as commercial products and applied to purify water. Most of agents works well and bring positive effects on environment. However, the use of some agents has shown problems relating to economic benefits and environment. The treatment cost and environmental safety evoke the increasing interests in not only developing countries but also in developed countries. To solve these problems, many researches have been carried out in the past decades focusing on improving materials for treatment. As a following tendency, the present study aims to understand mineralogy of the laterite samples located in different areas in Viet Nam and investigate their use as flocculating agents for clay suspended particle removal. Three laterite samples were collected to use for experiments in this study. The laterite sample collected in Thach That region (1-TT) performed the best flocculation efficiency followed by the laterite sample collected in Hoa Lac region (2-HL). The sample collected in Quynh Tam commune (3-HL) worked less efficiently than the other two samples. Geothite and hematite are considered to be the main components that are responsible for flocculation action. The study also suggested that the presence of clay sized quarts has an adverse effect on flocculation action.
\end{abstract}

Key words: clay particle, flocculation, geothite, hematite, laterite, water processing

\section{INTRODUCTION}

The suspended clay particles in water are main pollutants that cause turbidity in water environment. Removal of suspended particles is an essential operation in water treatment. Flocculation technique is a common way that is used to remove suspended materials from natural waters. In flocculation process, flocculating agents are added to overcome electrostatic repulsion and promote coalescence of the suspended particles to form large flocks that settle down rapidly (Tripathy and De Ranjan, 2006).

The synthetic agents, such as poly-diallyldimethylammoniumchloride (PDADMAC or Cat-Floc), used either alone or in combination with alum, have been reported to be effective in flocculation of negatively charged suspended particles in water (O'Melia, 1972; Faust and Aly, 1983). Long chain synthetic polymers are also popular flocculating agents to remove suspended materials via bridging and electrostatic patch mechanism (Tripathy and De Ranjan, 2006). Zhang et al. (2010) reported that a microbial polymer was effective for flocculating synthetic kaolinite suspensions. Chitosan, a product made from crab shell, is very effective to remove organic suspended materials (Tripathy and De Ranjan, 2006) with less negative effects on the environment.

\footnotetext{
1 Laboratory of Environmental Geochemistry, Division of Bioproduction Environmental Sciences, Department of Agroenvironmental Sciences, Graduate School of Bioresource and Bioenvironmental Sciences, Kyushu University

* Corresponding author (E-mail: wadasi@agr.kyushu-u.ac.jp)
}

The flocculating agents have brought undoubted benefits in water treatment. However, negative effects on the environment have been found by the use of some agents. Aluminum salts and synthetic polymers cause possible physiological effects on organisms (Nakanishi and Wada, 2007) as well as aluminum accumulation in the environment and its connection with Alzheimer disease (Stauber et al., 1999). Some natural substances such as chitosan and carboxymethyl cellulose are nontoxic to environment, available from renewable resources and very effective for pollutant removal (Divakaran and Pillai, 2001) but they are not stable against microbial attack during storage (Tripathy and De Rajan, 2006; Zhang et al., 2010) and may increase the biological oxygen demand of processed water if high dose is used. Therefore, flocculating agents with high treatment efficiency and less negative effects on the environment is needed for advanced water processing in open aquatic systems.

Natural flocculants derived from soil were reported by Nga et al. (2012b), which were effective in removing pollutants from water at a low treatment cost. The flocculant made from volcanic soil was found to be as effective as PAC for flocculating suspended clay particles in some natural reservoirs but their flocculation efficiency largely depended on clay mineralogy (Kuchibune et al., 2006; Nga et al., 2012a). Laterite, the in-situ weathering and decomposition products of rocks, is abundant in the tropical and sub-tropical regions and rich in sesquioxides $\left(\mathrm{Fe}_{2} \mathrm{O}_{3}\right.$ or $\left.\mathrm{Al}_{2} \mathrm{O}_{3}\right)$. Thus they are possibly applied for water treatment (Blight, 1997; Nga et al., 2012b). The study of Udoeyo et al. (2010) indicated strong absorption capacity for heavy metals of laterite materi- 
Table 1. Source of soil and clay samples

\begin{tabular}{|c|c|}
\hline Sample name & Source \\
\hline $\mathrm{T} 5$ & $\begin{array}{l}\text { B22 horizon of Haplustox in Nakhon } \\
\text { Ratchasima, Thailand }\end{array}$ \\
\hline $\mathrm{F}$ & Ap horizon of Fluvaquents in Fukuoka, Japan \\
\hline Kaolinite & Iriki mine, Kagoshima, Japan \\
\hline Montmorillonite & $\begin{array}{l}\text { Kunipia-F supplied by Kunimine Co., Tokyo, } \\
\text { Japan }\end{array}$ \\
\hline
\end{tabular}

als. Lateritic soils have been used as effective sorbents for arsenic in groundwater (Maji et al., 2006; Rahman et al., 2008; Maiti et al., 2010). In addition, laterite adsorbs phosphorous in natural lakes and landfills (Zhang et al., 2011). Nga et al. (2012b) investigated removal capacity of kaolinite from water by laterite material that was collected in Viet Nam.

The laterite is an abundantly distributed in many regions in Viet Nam due to strong laterization. The characteristics of laterite would be different depending on regional climate and geology. The laterite materials are of high potential use in environmental treatments, but the laterite materials in Viet Nam have not been received due attention. Mineralogy of materials has been considered as an important factor affecting the removal of suspended particles (Nga et al., 2012a). Therefore, the present study aims to investigate mineralogy of laterite samples from Viet Nam and their use as a flocculating agent to remove suspended clay particles.

\section{MATERIALS AND METHODS}

\section{Laterite samples}

Three laterite samples, namely 1-TT, 2-HL and 3-QT, were collected from lateric soil zones in Viet Nam indicated in Fig 1. The 1-TT sample was collected from a layer at a depth of $1.5 \mathrm{~m}$ in Thach That town where completely weathered laterite distributes. The original sample is a hard block with dark yellow color. The $2-\mathrm{HL}$ sample was found in excavated soil at a construction site. It is a hard block containing red solid gravels. The 3-QT sample was taken from a laterite profile at a depth of $0.5 \mathrm{~m}$ from the surface. The raw sample was a hard block with black grey color.

The original samples were washed with tap water and air-dried at a room temperature. They were gently crushed to pass through a 2-mm screen. Aliquot of the treated samples was mixed well with distilled water, and

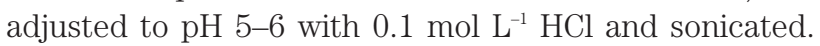
The prepared three flocculant samples had dry matter content of 131, 127 and 91 g/Lfor1-TT, 2-HL and 3-QT, respectively.

\section{Clay suspensions}

Clay suspensions used for flocculation tests were prepared from two soil samples and two specimen clays (Table 1) following the procedure described by Nga et al. (2012a). A five-gram portion of the soil or clay sample was mixed with $1 \mathrm{~L}$ of deionized water and sonicated

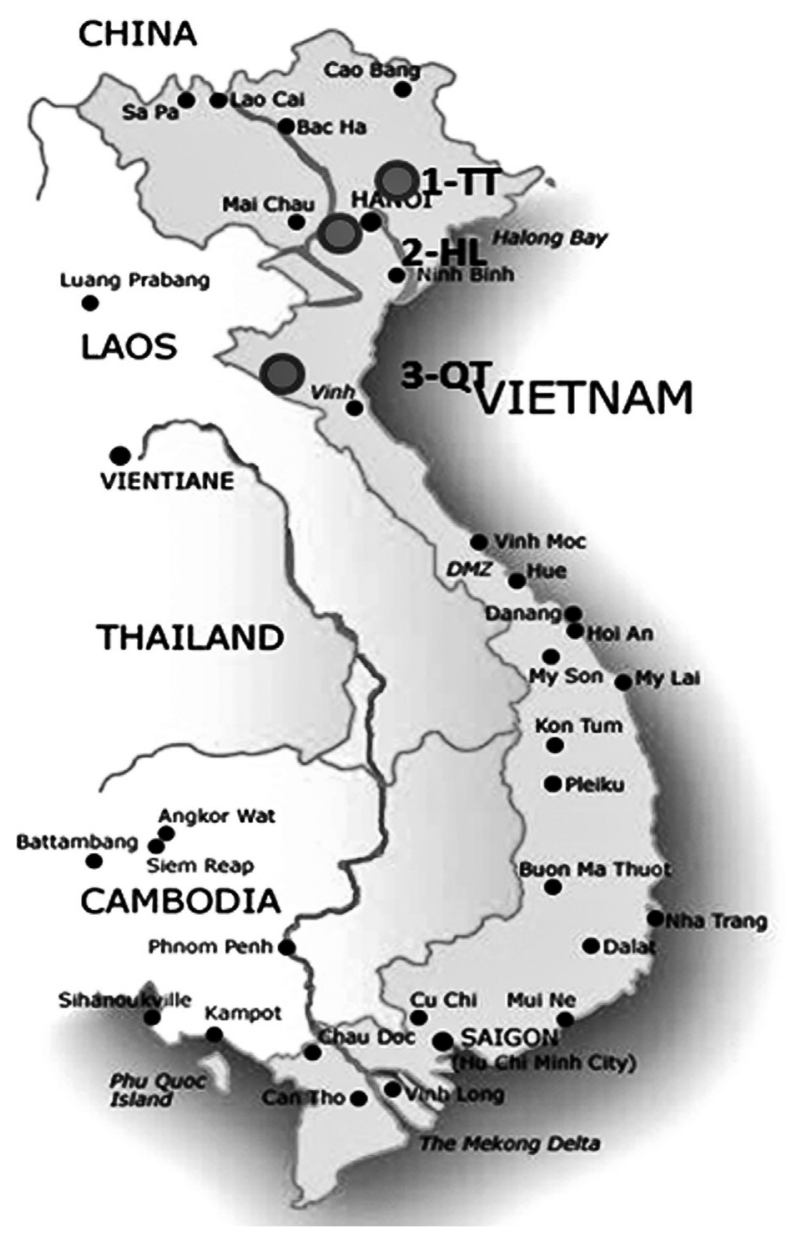

Fig. 1. Location of sampling site.

for 15 min after $\mathrm{pH}$ adjustment to about 8 with $0.1 \mathrm{~mol} / \mathrm{L}$ $\mathrm{NaOH}$. The dispersed suspension was put into sedimentation cylinder and the fraction having equivalent spherical diameter of $<2 \mu \mathrm{m}$ was separated by siphoning. This step was repeated using several portions of the samples to obtain sufficient amount of clay suspension for flocculation tests. The separated stock clay suspensions were kept in a polypropylene bottle with fitted stopper and diluted with deionized water just before use.

\section{Mineralogy and surface characteristic analysis of clay suspensions and laterite samples}

Mineralogy of the laterite samples were analyzed for four components (clay, silt, fine sand and coarse sand) by X-ray diffraction (RINT-2000V, Rigaku) following the procedure of Nga et al. (2012a).

Mineralogical analysis of the clay suspensions by $\mathrm{X}$-ray diffraction was carried out following the procedure described by Wada and Umegaki (2001) with a $\mathrm{Cu} \mathrm{K}_{\alpha}$ radiation at $40 \mathrm{kV}$ and $20 \mathrm{~mA}$.

Exchangeable cation composition was determined by $1 \mathrm{~mol} / \mathrm{L} \mathrm{NH}_{4} \mathrm{OAc}$ extraction. For clay suspensions, the principle of Nga et al. (2012) was applied. A clay suspension containing $200 \mathrm{mg}$ of clay was placed on a $0.1 \mu \mathrm{m}$ membrane filter and washed with $50 \mathrm{~mL}$ of the $\mathrm{NH}_{4} \mathrm{OAc}$ solution under suction. For laterite samples, the method 
of Muramoto et al. (1992) was applied. A Two gram portion of a laterite sample was extracted three times with $30 \mathrm{~mL}$ the $\mathrm{NH}_{4} \mathrm{OAc}$ solution. The extract was analyzed for $\mathrm{Ca}^{2+}, \mathrm{Mg}^{2+}, \mathrm{Na}^{+}$and $\mathrm{K}^{+}$by atomic absorption spectroscopy (Z2300, Hitachi, Japan).

Particle size distribution of the laterite samples was determined by siphoning method. The air-dried samples after organic matter digestion were separated by sonication for 15 minutes. Clay, silt and sand fractions were collected after respective settling time by siphoning.

Surface charge of laterite samples was determined by serial potentiometric titration method. A Five gram portion of the sample was equilibrated with $\mathrm{NaCl}$ solutions having different $\mathrm{pHs}$ for 4 hours keeping ionic strength at $0.005,0.02$ or $0.1 \mathrm{~mol} / \mathrm{L}$. Proton and hydroxide ion adsorption by laterite was calculated from $\mathrm{pH}$ difference between before and after reaction, then $\mathrm{pH}_{\mathrm{PZSE}}$ were determined from the intersection point of the curves where the proton hydroxide adsorption were plotted against $\mathrm{pH}$ at different ionic strengths. The surface charge was set to zero at $\mathrm{pH}_{\mathrm{PZSE}}$ and for other $\mathrm{pH}$ surface charges were determined by shifting the proton and hydroxide adsorption isotherms.

\section{Thermal analyses}

Differential thermal and gravimetric analysis (DTA-TG) was carried out simultaneously using the system of Rigaku Thermo plus EVO. The samples were heated from 20 to $1000^{\circ} \mathrm{C}$ for 100 minutes. The amount of sample used in each test was $10 \mathrm{mg}$.

\section{Flocculation experiments}

The flocculation experiments were performed by a jar tester (MJS-3H, Miyamoto Co., Japan) in a room at $20-24^{\circ} \mathrm{C}$ following the procedure of Nga et al. (2012a). A four hundred $\mathrm{mL}$ portion of a $500 \mathrm{mg} / \mathrm{L}$ clay suspension was placed in a $500 \mathrm{ml}$ tall beaker and the impeller rod was put in the suspension. Immediately after the addition of predetermined dose of laterite flocculants, the suspension was stirred at a speed of $300 \mathrm{rpm}$ for $3 \mathrm{~min}$ and at $50 \mathrm{rpm}$ for $5 \mathrm{~min}$. The flocks were allowed to settle for $30 \mathrm{~min}$. A $10 \mathrm{ml}$ portion of the supernatant was collected from $2 \mathrm{~cm}$ below the water surface and absorbance was measured at a wave length of $660 \mathrm{~nm}$ by a spectrophotometer (U1900, Hitachi, Japan). All of the tests were carried out in triplicate.

\section{RESULTS AND DISCUSSION}

\section{Mineralogy and surface charge characteristics of laterite samples}

$\mathrm{X}$-ray diffraction patterns of the Mg-saturated and glycerol-solvated clay fractions and fine sand fractions of three laterite samples are shown in Fig. 2. The clay fractions of the 1-TT and 2-HL samples showed fairly strong peaks at $0.7,0.418,0.35$ and $0.269 \mathrm{~nm}$, indicating that these samples contain kaolinite and goethite and hematite. In addition, the 1-TT sample showed weak peak at $1.4 \mathrm{~nm}$, indicating that it contain small amount of non-expandable 2:1 layer silicates. The weak peak at
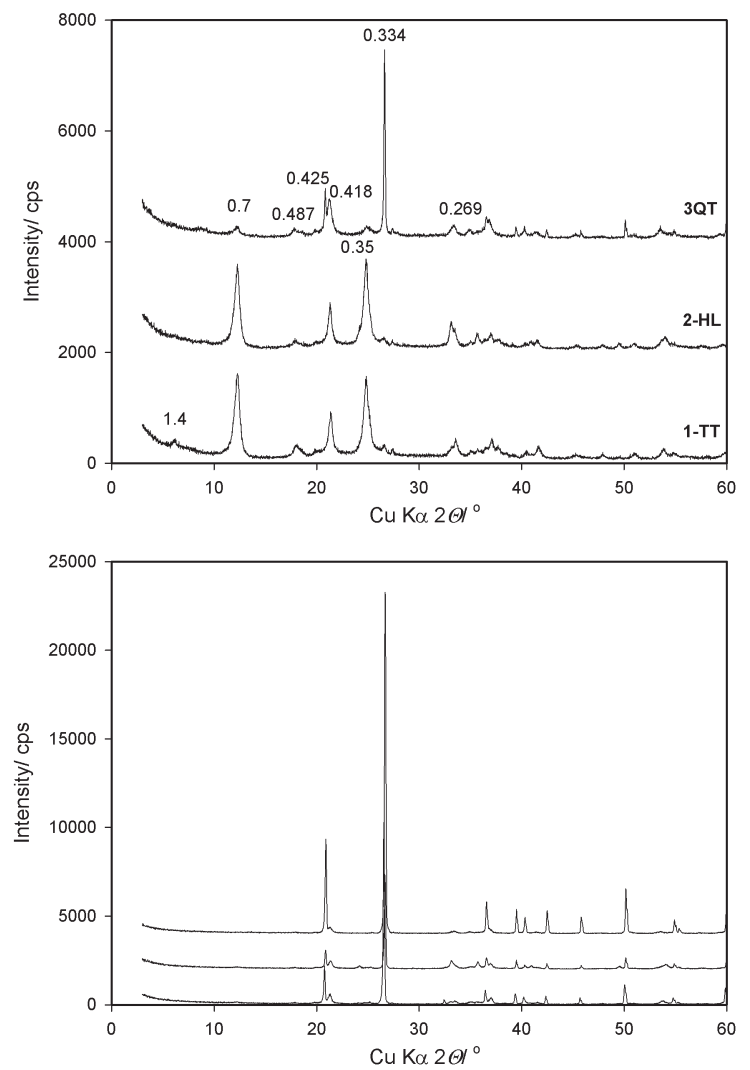

Fig. 2. X-ray diffraction pattern of laterite samples: Clay fraction (top) and Fine sand fraction bottom.
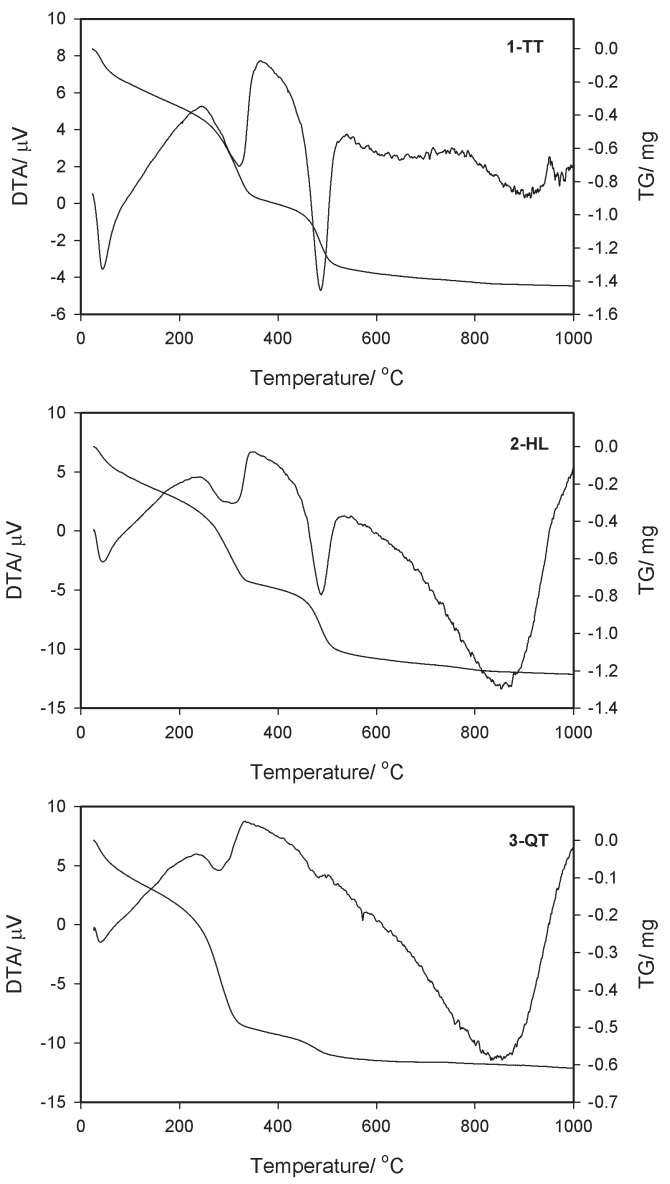

Fig. 3. Results of differential thermal analysis and thermogravimetric analysis. 
$0.487 \mathrm{~nm}$ indicates that all the samples contain gibbsite. The 3-QT sample showed a significantly different mineralogy in that it is dominated by quartz and contained much less amount of kaolinite but it contained goethite and hematite. The dominance of 0.425 and $0.334 \mathrm{~nm}$ peaks in the X-ray diffraction patters for fine sand samples indicate that the major mineral in the fine sand fraction is quartz. The small but distinct peak at 0.418 and $2.69 \mathrm{~nm}$ shows that the fine sand fractions also contain goethite and hematite. The silt and coarse sand fractions exhibited similar X-ray patterns.

The results of thermal analyses are shown in Fig. 3. All the samples showed clear endothermic peaks centered at around $50,320^{\circ} \mathrm{C}$ and corresponding weight losses. The 1-TT and 2-HL samples exhibited an additional large endothermic peak at $480^{\circ} \mathrm{C}$ but the $3-\mathrm{QT}$ sample showed only a faint peak at that temperature. The end thermic peak at $50^{\circ} \mathrm{C}$ obviously came from desorption of adsorbed water. And the peaks at 320 and $480^{\circ} \mathrm{C}$ are assigned to dehydration reaction of hydroxide minerals and kaolinite, respectively. Since goethite dehydrates at lower temperature than gibbsite, the endothermic peak centered at around $320^{\circ} \mathrm{C}$ suggests that the contribution of gibbsite was larger. These results harmonize with $\mathrm{X}$-ray diffraction patterns shown in Fig. 1, particularly in that the 3-QT sample showed very weak diffraction peak at $0.7 \mathrm{~nm}$. The $2-\mathrm{HL}$ and $3-\mathrm{QT}$ samples showed large endothermic peaks at around $840^{\circ} \mathrm{C}$ but they did not accompany weight loss. The origin of these endothermic peaks was not identified.

The dehydration reaction of gibbsite and kaolinite are expressed as

Table 2. Some physical and chemical properties of laterite samples

\begin{tabular}{ccccccccc}
\hline No & $\mathrm{pH}_{\mathrm{H} 2 \mathrm{O}}$ & $\mathrm{pH}_{\mathrm{kcl}}$ & $\begin{array}{c}\mathrm{TOC} \\
(\%)\end{array}$ & $\begin{array}{c}\text { Clay } \\
(\%)\end{array}$ & $\begin{array}{c}\text { Silt } \\
(\%)\end{array}$ & $\begin{array}{r}\text { Fine } \\
\text { sand } \\
(\%)\end{array}$ & $\begin{array}{c}\text { Coarse } \\
\text { sand } \\
(\%)\end{array}$ & $\begin{array}{c}\mathrm{ECEC} \\
\left(\mathrm{cmol}_{\mathrm{c}} /\right. \\
\mathrm{kg})\end{array}$ \\
\hline 1-TT & 5.30 & 5.03 & 0.18 & 67.42 & 6.29 & 7.71 & 18.58 & 1.36 \\
$2-\mathrm{HL}$ & 5.56 & 4.95 & 0.13 & 57.03 & 6.24 & 9.89 & 26.83 & 1.00 \\
$3-\mathrm{QT}$ & 5.35 & 5.18 & 0.13 & 30.93 & 8.04 & 24.65 & 36.38 & 0.77
\end{tabular}

$$
2 \mathrm{Al}(\mathrm{OH})_{3}=\mathrm{Al}_{2} \mathrm{O}_{3}+3 \mathrm{H}_{2} \mathrm{O}
$$

and

$$
\mathrm{Si}_{4} \mathrm{Al}_{4} \mathrm{O}_{10}(\mathrm{OH})_{8}=\mathrm{SiO}_{2} \cdot \mathrm{Al}_{2} \mathrm{O}_{3}+4 \mathrm{H}_{2} \mathrm{O}
$$

The weight loss from 200 to $400^{\circ} \mathrm{C}$ was about $0.5 \mathrm{mg}$ for all three samples. If this came from the dehydration of gibbsite, the stoichiometry in the reaction (1) gives the gibbsite weight of $1.4 \mathrm{mg}$ in $10 \mathrm{mg}$ sample. Similarly, the weight of kaolinite in is estimated to be $1.4 \mathrm{mg}$ for the 1-TT and 2-HL samples and $0.71 \mathrm{mg}$ for the $3-\mathrm{QT}$ sample.

Basic chemical properties are summarized in Table 2. The $\mathrm{pH}\left(\mathrm{H}_{2} \mathrm{O}\right)$ was in a range from 5.3 to 5.6 and the $\mathrm{pH}$ $(\mathrm{KCl})$ was similar, indicating that the samples contained little exchangeable Al. The 1-TT sample showed the highest clay content of $67 \%$ followed by the $2-\mathrm{HL}$ and 3-QT samples. The clay content of the 3-QT sample was only $30 \%$ and it had fairly high sand content. Although the clay content was high, the effective cation exchange capacity, i. e. the sum of exchangeable cations, was very low. This is a reflection of the virtual lack in 2:1 type layer

\begin{tabular}{|c|c|c|}
\hline Sample & Fraction & Major minerals \\
\hline \multirow{4}{*}{$1-\mathrm{TT}$} & Clay & $\begin{array}{l}\text { Gibbiste, Kaolinite, Goethite, Hematite, } \\
\text { Vermiculite }\end{array}$ \\
\hline & Silt & Quartz, Kaolinite, Goethite, Hematite \\
\hline & Fine sand & Quazt; Geothite, Hematite \\
\hline & Coarse sand & Quartz, Goethite, Hematite \\
\hline \multirow{4}{*}{ 2-HL } & Clay & Gibbsite, Kaolinite, Goethite, Hematite \\
\hline & Silt & Quartz, Goethite, Hematite \\
\hline & Fine sand & Quartz, Goethite, Hematite \\
\hline & Coarse sand & Quartz, Goethite, Hematite \\
\hline \multirow{4}{*}{ 3-QT } & Clay & $\begin{array}{l}\text { Gibbiste, Goethite, Hematite, Quartz, } \\
\text { Kaolinite }\end{array}$ \\
\hline & Silt & Quazt, Goethite, Hematite \\
\hline & Fine sand & Quazt, Goethite, Hematite \\
\hline & Coarse sand & Quatz, Goethite, Hematiet \\
\hline
\end{tabular}

Table 3. Approximate mineralogical composition of laterite samples
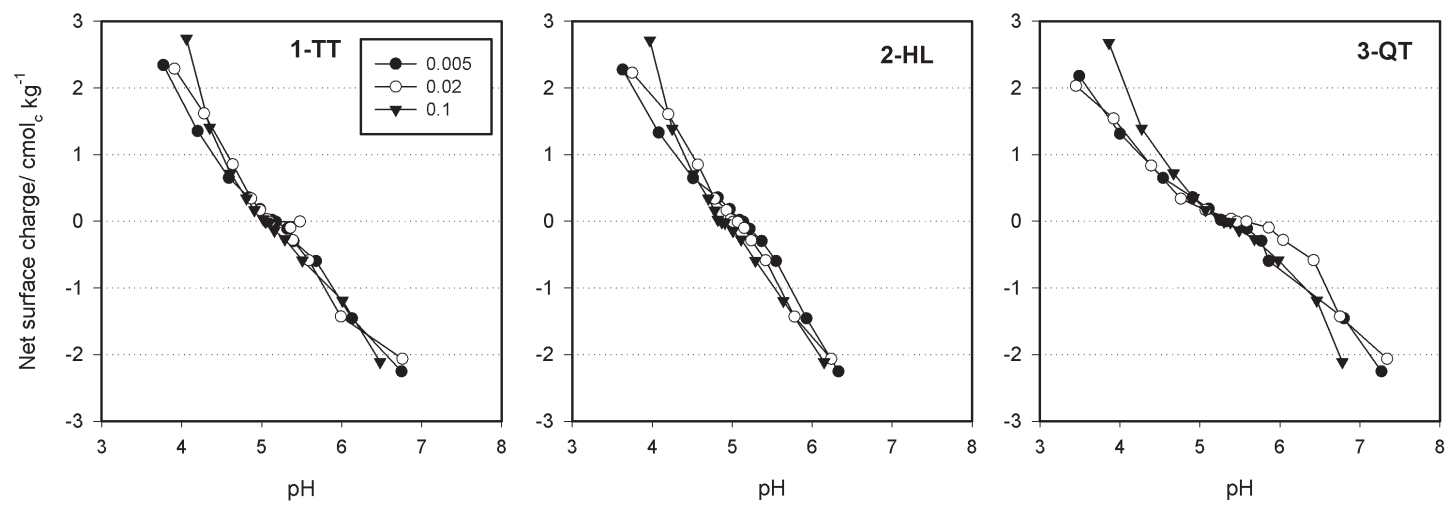

Fig. 4. Surface charge characteristics of laterite samples. 
silicate minerals as indicated by X-ray diffraction (Fig. 2).

Fig. 4 shows the surface charge characteristics of laterite samples used in the present study, where the net surface charge was plotted against solution $\mathrm{pH}$. The net charge decreased as $\mathrm{pH}$ increased and the sign of the net charge reversed at pHs 5.1, 5.0 and 5.4 for the $1-\mathrm{TT}$, 2-HL and 3-QT samples, respectively. These $\mathrm{pH}$ values, i. e. the point of zero net charge (PZNC) were not much different from $\mathrm{pH}$ values measured in water (Table 2). Since PZNC for goethite and gibbsite lie around $\mathrm{pH}$ 8, the observed lower PZNC values may be due to the presence of kaolinite and quartz.

Based on the mineralogical and chemical data, the approximate mineralogical composition of the laterite samples is summarized in Table 3.

\section{Mineralogy and colloidal properties of clay suspen- sions}

The X-ray diffraction patterns of the soil clay samples used for the flocculation tests are shown in Fig. 5. The strong peak at 0.7 and $0.35 \mathrm{~nm}$ in the T5 sample indicate that kaolinite predominates. The broad at $1.7-1.9 \mathrm{~nm}$ and $1.0 \mathrm{~nm}$ in the $\mathrm{F}$ sample show that it contains smectite and micaseous minerals. The approximate contents of layer silicate minerals and quartz that were estimated by the procedure described by Mosslehuddin (1998), Nguyen (2008) and Wada and Greenland (1970) were already reported by Nga et al. (2012a).

Properties of the clay suspensions used for the flocculation tests were summarized in Table 4. The suspension $\mathrm{pH}$ ranged from 6.81 to 6.86. The electric conductiv-

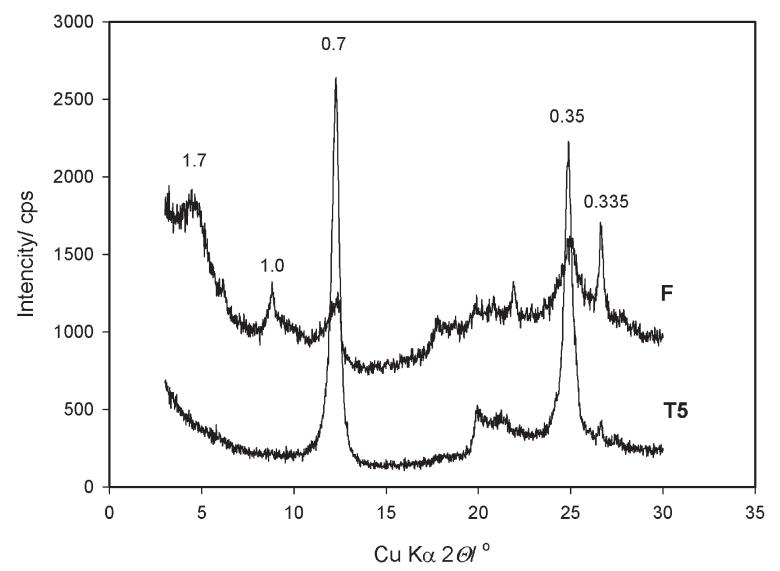

Fig. 5. X-ray diffraction patterns of soil clay samples used for flocculation tests. ity was low and not much different among samples. The T5 sample had the smallest average particle diameter of $86 \mathrm{~nm}$, while the kaolinite sample had the largest average diameter of $384 \mathrm{~nm}$. The ECEC of the suspended clays was in a large range from 3.7 to $99 \mathrm{cmol}_{\mathrm{c}} / \mathrm{kg}$. The fraction of $\mathrm{Na}$ was the largest among the exchangeable cations because $\mathrm{NaOH}$ was added for $\mathrm{pH}$ adjustment (Nga et al., 2012a).

\section{Flocculation tests}

The fluffy flocks formed when the flocculants were added and clay suspensions were vigorously stirred at a speed of $300 \mathrm{rpm}$. During the continued stirring at $50 \mathrm{rpm}$, the flocks grew in size and they loosely deposited on the bottom of the beaker after $30 \mathrm{~min}$ of the standing time. A $10 \mathrm{~mL}$ portion of the supernatant was sampled from a depth of $2 \mathrm{~cm}$ from the surface and its absorbance at $660 \mathrm{~nm}$ was measured. The results of the flocculation experiments are graphically presented in Fig. 6, where the averaged relative absorbance at three replications was plotted against the flocculant dose. In general, the absorbance decreased as the flocculant dose increased and then increased again past optimum dose. The reincrease in absorbance is probably due to the presence of the excess flocculent and/or re-dispersed clay particles (Nga et al., 2012a). This observation was also in good agreement with the results by Nga et al. (2012b) on the kaolinite removal from water by volcanic and laterite materials. The montmorillonite suspension showed different response when the 3-QT slurry was added in that the absorbance exceeded that of the original montmorillonite suspension by about $20 \%$ (Fig. 6).

The lowest relative absorbance of about 0.01 indicates that $99 \%$ of the suspended clay particles were removed from the suspension. Considering the $\mathrm{pHs}$ of the clay suspensions and the PZNC the mutual flocculation of the added laterite and clay particles were due to the charge neutralization. The suspension pHs during flocculation experiment were close to those of the original clay suspensions, i. e. around 6.8 , because the volume of the added flocculants remained mostly $<10 \%$ of the volume of the clay suspension. Since the PZNCs are around 5 , the net surface charge is negative at round $\mathrm{pH}$ 6.8. This is seemingly contradictory to the charge neutralization. But it is not unreasonable to expect the mechanism because gibbsite and goethite would have had positive surface charge even at pH 7. Follett (1965) proved that electrostatic attraction force was dominated in retention of amorphous and colloidal ferric hydroxides

Table 4. Colloidal properties of clay samples

\begin{tabular}{|c|c|c|c|c|c|c|c|c|}
\hline \multirow{2}{*}{ Samples } & \multirow{2}{*}{$\mathrm{pH}$} & \multirow{2}{*}{$\begin{array}{c}\mathrm{EC} / \\
\mathrm{dS} \mathrm{m} \mathrm{m}^{-1}\end{array}$} & \multicolumn{4}{|c|}{ Exchangeable cations $/ \mathrm{cmol}_{c} \mathrm{~kg}^{-1}$} & \multirow{2}{*}{$\begin{array}{c}\text { Average particle } \\
\text { size/nm }\end{array}$} & \multirow{2}{*}{$\begin{array}{l}\text { Average zeta } \\
\text { potential } / \mathrm{mV}\end{array}$} \\
\hline & & & $\mathrm{Na}^{+}$ & $\mathrm{K}^{+}$ & $\mathrm{Ca}^{+2}$ & $\mathrm{Mg}^{2+}$ & & \\
\hline T5 & 6.82 & 0.02 & 3.35 & 0.40 & 1.68 & 0.72 & 86 & -45.1 \\
\hline $\mathrm{F}$ & 6.81 & 0.03 & 4.95 & 2.11 & 17.22 & 5.53 & 187 & -36.6 \\
\hline Montmorillonite & 6.86 & 0.04 & 77.41 & 1.96 & 14.83 & 4.82 & 224 & -55.7 \\
\hline Kaolinite & 6.86 & 0.04 & 2.75 & 0.21 & 0.40 & 0.31 & 384 & 16.7 \\
\hline
\end{tabular}



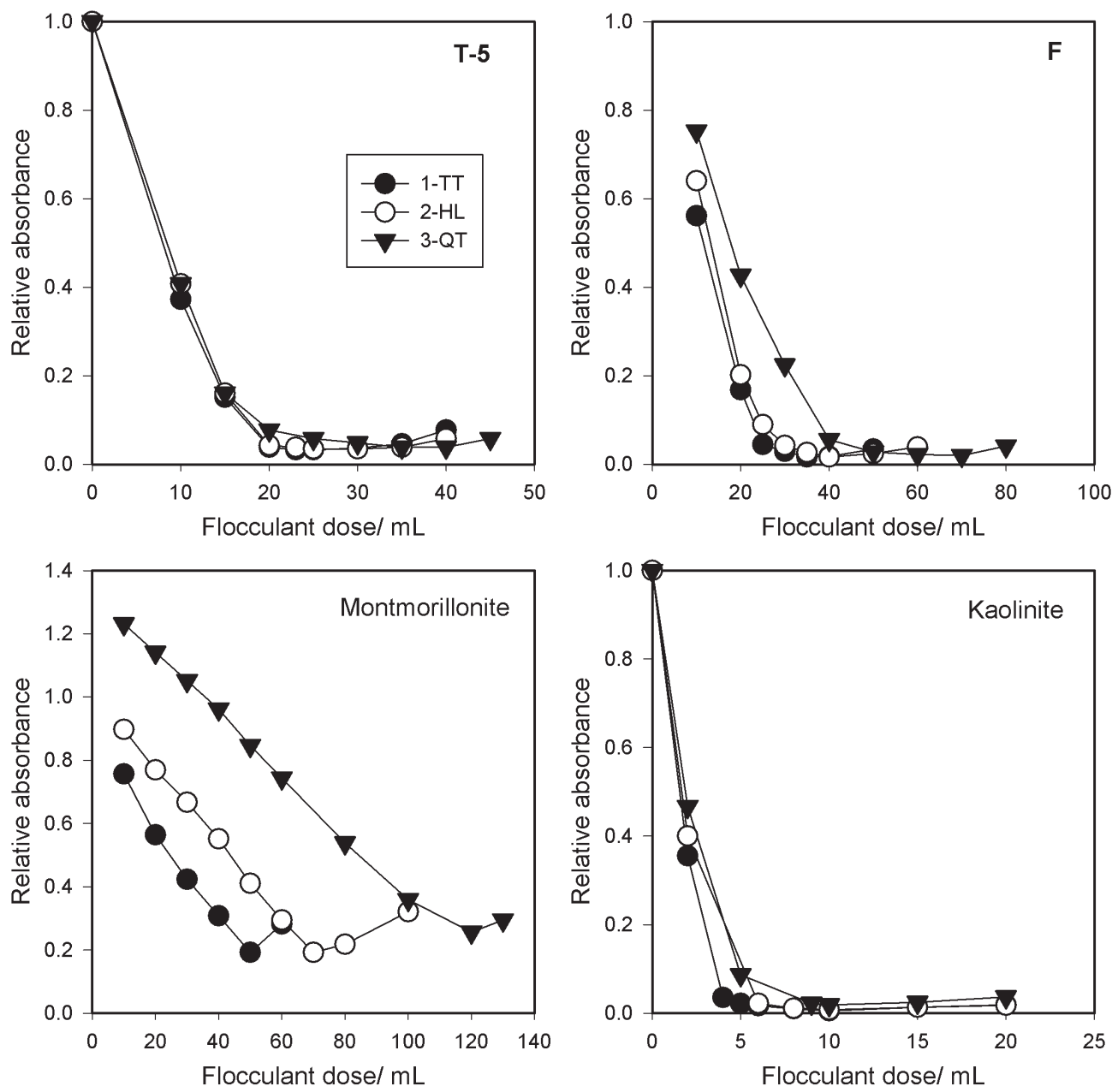

Fig.6. Results of flocculation tests showing the relative absorbance of the suspension after flocculant addition and flocculant dose.

by kaolinite. He also concluded that no bonding rearrangement occurred upon sorption of ferric colloids onto kaolinite. Weiss and Russow (1963) also indicated a similar association behavior of positively charged AgI particles by clay particles.

The results of the flocculation tests indicated that the amount of flocculant required to achieve the lowest absorbance was different for clay suspensions. The respective optimum dose of the flocculant made from 1-TT, 2-HL and 3-QT were 50, 70 and $120 \mathrm{ml}$ for montmorillonite, 35, 40 and $60 \mathrm{ml}$ for the $\mathrm{F}$ sample, 20, 25 and $35 \mathrm{ml}$ for $\mathrm{T} 5$ sample and 5, 6, and $9 \mathrm{ml}$ for kaolinite. Nga et al. (2012a) reported that the mineralogical characteristics of clay suspensions affected the flocculation efficiency. According their experimental results, suspensions containing smectite required larger flocculant dose (Nga et al., 2012a). The present results are in accordance with theirs in that the T5 sample and kaolinite having low ECEC needed small amount of flocculants whereas montmorillonite and the $\mathrm{F}$ clay sample needed much more flocculant dose. Another factor for the very high flocculation efficiency for kaolinitic suspensions is that kaolinite has PZNC of about 3.0 as interpreted by Nga et al. (2012b) and Horikawa (1976).

The flocculation performance of the three laterite flocculants was obviously different. The 1-TT sample gave the highest flocculation efficiency followed by the 2-HL sample, and 3-QT and this trend was common to the results from all four clay suspensions. The trend was marked for montmorillonite (Fig. 6). The gibbsite and goethite content of the 3-QT laterite seems comparable with those of other laterite samples (Figs. 2 and 3). The surface charge characteristics for the three laterite samples were also similar (Fig. 4). One possible reason for the observed lower flocculation efficiency is the presence of a significant amount of clay sized quartz as indicated by the X-ray diffraction pattern in Fig. 2. The fine quartz particles may have left in the clay suspensions without interacting with negatively charged clay particles. This may explain the relative absorbance $>1$ observed for montmorillonite (Fig. 6).

\section{CONCLUSIONS}

The flocculants made from laterites in Viet Nam are able to remove suspended clay particles via charge neutralization mechanism. The flocculation efficiency significantly depends on mineralogy and surface charge characteristics of both clay suspensions and laterite flocculants. Iron oxide minerals, e. g., geothite and hematite in 
the laterite are considered to be the factors contributing to flocculation.

\section{ACKNOWLEDGEMENTS}

This study was supported in part by a Grant-in-Aid for scientific research from the Japanese Society for Promoting Sciences (\#21380048 and \#22246064).

\section{REFERENCES}

Blight, G. E. 1997 Mechanics of residual soil. Balkema, Rotterdam (Netherland)

Divakaran, R. and S. Pillai 2001 Flocculation of kaolinite suspensions in water by chitosan. Wat. Res, 16: 3904-3908

Faust S. D. and O. M. Aly 1983 Removal of particulate matter by coagulation. In "Chemistry of water treatment", Butterworth Publisher, Boston, pp. 277-367

Horikawa, Y. 1976 Electrophoretic mobility of binary mixtures of imogolite and some other clay minerals in aqueous suspensions. Clay Sci., 5: 43-50

Kuchibune, A., T. Morimoto and S. -I. Wada 2006 Preparation of efficient coagulant from clays. Proc. $16^{\text {th }}$ Symposiumon GeoEnvironments and Geotechniques., pp. 63-66 (in Japanese)

Maiti, A., K. Jayanta, B. Kumar, D. Sirshendu 2010 Synthetic and natural groundwater using acid active laterite. $J$. Environmental progress and sustainable energy, 4: 457470

Maji, S. K., A. J. Pal, and T. Pal 2006 Arsenic removal from reallife groundwater by absorption on laterite soil. J. Hazad. Mater., 151: 811-820

Moslehuddin, A. Z. M. 1998 Mineralogy and potassium chemistry of Bangladesh paddy soil. Ph. D. dissertation. Kyushu
University, Japan

Nakanishi, R. and S. -I. Wada 2007 Reactivity with phosphate and phytotoxicity of hydroxylaluminosilicate ions synthesized by instantaneous mixing of aluminum chloride and sodium orthosilicate solutions. Soil Sci. Plant Nutr., 53: 545-550

Nga, N. T. H., Y. Ienaga, Y. Mori and S. -I. Wada 2012a Effects of mineralogy of suspended materials on performance of weathered volcanic ash-based flocculant. J. Clay Sci., 16: 33-39

Nga, N. T. H., Y. Mori and S. -I. Wada 2012b Removal of kaolinite suspensions from water using soil based flocculants. Collaborative project for Soil and water conservation in Southeast Asian watersheds: 34-38

O'Melia, C. R. 1972 Physicochemical Processes for water quality control. Wiley, New York.

Rahman, I. M. M., K. Iwakabe and J. Kawasaki 2008 Laterite a potential alternative for removal of ground water arsenic. Appl. Sci. Enviro. Manage., 1: 93-100

Stauber, J. L., T. M. Florence, C. M. Davis, M. S. Adam and S. J. Buchana 1999 Bioavailability of $\mathrm{Al}$ in alum-treated drinking water. J. Am. Water Works Assoc., 91: 84-93

Tripathy, T. and B. De Ranjan 2006 Flocculation: A new way to treat the waste water. J. Phys. Sci., 10: 93-127

Udoeyo, F. F., B. Robert, H. Inyang and B. Sunyoung 2010 Imo lateritic soil as an absorbent for heavy metals. IJ. RRAS, $\mathbf{1}$ 4-5

Wada, K. and D. J. Greenland 1970 Selective dissolution and differential infrared spectroscopy for characterization of amorphous constituents in soil clay. Clay Miner., 8: 241-254

Weiss, A. J. and Russow 1963 The location of exchangeable cations on kaolinites Proc. Int. Clay Conf., Stockholm, 1: 203-213

Zhang, Z., S. Xia, S. J. Zao and J. Zhang 2010 Characterization and flocculation mechanisms of high efficiency microbial flocculant TJ-F1 from Proteus mirabilis. J. Colloids Sturf., 75 $247-251$ 